\title{
Spotlight on math anxiety
}

This article was published in the following Dove Press journal:

Psychology Research and Behavior Management

\author{
Silke Luttenberger ${ }^{\prime}$ \\ Sigrid Wimmer ${ }^{2}$ \\ Manuela Paechter ${ }^{2}$ \\ 'Institute for Educational Sciences \\ and Educational Research, University \\ of Teacher Education Styria, Graz, \\ Austria; ${ }^{2}$ Educational Psychology Unit, \\ Institute of Psychology, University of \\ Graz, Graz, Austria
}

Correspondence: Manuela Paechter University of Graz, Institute of Psychology, Universitaetsplatz 2, Graz 8010 , Austria

Tel +43316380 8542

Email manuela.paechter@uni-graz.at
Abstract: Anxiety disorders are some of the most widespread mental health issues worldwide. In educational settings, individuals may suffer from specific forms of test and performance anxiety that are connected to a knowledge domain. Unquestionably, the most prominent of these is math anxiety. Math anxiety is a widespread problem for all ages across the globe. In the international assessments of the Programme for International Student Assessment (PISA) studies, a majority of adolescents report worry and tension in math classes and when doing math. To understand how math anxiety takes effect, it has to be regarded as a variable within an ensemble of interacting variables. There are antecedents that facilitate the development of math anxiety. They concern environmental factors such as teachers' and parents' attitudes toward their students' and children's ability in math, societal stereotypes (eg, on females' math abilities), or personal factors such as traits or gender. These antecedents influence a number of variables that are important in learning processes. Math anxiety interacts with variables such as self-efficacy or motivation in math, which can intensify or counteract math anxiety. Outcomes of math anxiety concern not only performance in math-related situations, they can also have long-term effects that involve efficient (or not-so-efficient) learning as well as course and even vocational choices. How can math anxiety be counteracted? A first step lies in its correct diagnosis. Questionnaires for the assessment of math anxiety exist for all age groups, starting at primary education level. Help against math anxiety can be offered on different levels: by educational institutions, by teachers and a change in instructional approaches, by parents, or by the affected person. However, much more research is needed to develop effective measures against math anxiety that are tailored to an individual's characteristics and needs.

Keywords: math anxiety, performance in mathematics, diagnosis of math anxiety, measures against math anxiety

\section{Aims}

This overview on math anxiety pursues the following aims:

- To describe the phenomenon of math anxiety, including information on its prevalence and on how it differs from other forms of anxiety.

- To explain which variables (antecedents) influence the occurrence of math anxiety, which variables interact with it, and what are the (educational) outcomes of math anxiety. These different types of variables are sorted and structured in a framework on math anxiety. 
- To introduce instruments for the measurement of math anxiety in different age groups.

- To describe possible means to prevent or reduce math anxiety.

\section{Introduction}

Anxiety disorders are some of the most widespread mental health-care problems worldwide. ${ }^{1}$ In a 2006 literature review including more than 40 studies from different countries, prevalence rates for anxiety disorders were nearly $17 \%$ (taking into consideration the major types such as generalized anxiety disorder, obsessive-compulsive disorder, panic disorder, phobia, posttraumatic stress disorder, and social anxiety disorder). ${ }^{2}$ Compared to men, women have higher prevalence rates across all anxiety-disorder categories. Moreover, anxiety disorders involve not only adults. They are also the most common mental health problems experienced by young people. ${ }^{3}$

In educational settings, anxiety can have detrimental effects on learners. It involves feelings in specific situations, such as examinations, as well as overall learning, and even lifelong academic and vocational development. Along with more overarching anxiety disorders, individuals may suffer from specific forms of test and performance anxiety that are connected to a knowledge domain. Clearly, the most prominent of these disorders is math anxiety. ${ }^{4}$

Math anxiety is a widespread, worldwide problem affecting all age groups. Approximately $93 \%$ of adult US-Americans indicate that they experience some level of math anxiety. ${ }^{4}$ Estimations are that approximately $17 \%$ of the US-American population suffers from high levels of math anxiety. ${ }^{5}$ In a sample of adolescent apprentices in the United Kingdom, approximately $30 \%$ of the study participants reported high math anxiety, and a further $18 \%$ were at least somewhat affected by it. ${ }^{6}$ The most extensive set of data is provided by the Programme for International Student Assessment (PISA) studies. In its 2012 assessments, across the 34 participating Organisation for Economic Co-operation and Development (OECD) countries, 59\% of the 15- to 16-year-old students reported that they often worry math classes will be difficult for them; $33 \%$ reported that they get very tense when they have to complete math homework; and another $31 \%$ stated they get very nervous doing math problems. ${ }^{7}$

Math anxiety has been mainly investigated in educational settings, and research has seldom been linked to clinical research on anxiety disorders. In the diagnostic systems for mental disorders - the Diagnostic and Statistical Manual of Mental Disorders (DSM) ${ }^{8}$ and the International Classification of Diseases (ICD) ${ }^{9}$ - it is not included as a separate category, but would rather be subsumed under generalized anxiety disorder or social anxiety disorder. ${ }^{1}$ Many individuals who claim to be affected by math anxiety probably would not meet the DSM criteria for an anxiety disorder. Yet, research shows that math anxiety affects individuals of all ages in academic situations as well as in their academic success and well-being. Moreover, math anxiety is distinct from anxieties in other subjects or general test anxiety; for example, research on anxiety in related subjects such as math and statistics shows that, to a large degree, math anxiety and statistics anxiety are independent of each other and have different effects on learners. ${ }^{10}$

Math anxiety has been defined as feelings of apprehension and increased physiological reactivity when individuals deal with math, such as when they have to manipulate numbers, solve mathematical problems, or when they are exposed to an evaluative situation connected to math. ${ }^{10-12}$ Many studies and measurement instruments assume at least two assessment-related dimensions of math anxiety: anxiety experienced when taking a test, and anxiety experienced in the classroom. ${ }^{11,13}$ Math anxiety experienced in the classroom may also include a sub-facet related to the fear of math teachers. ${ }^{14}$ Other studies add the numerical anxiety content-related dimension to test and classroom math anxiety. This describes anxiety that occurs when undertaking math operations and manipulating numbers. ${ }^{15,16}$ Some researchers further differentiate math anxiety according to different situations in which math tasks are encountered, such as homework in math or mathematical tasks in daily life. ${ }^{17}$ Although theories and measurement instruments vary considerably in the differentiation of math anxiety, nearly all of them agree on three facets found within it: test, classroom, and numerical anxiety.

Math anxiety describes an enduring, habitual type of anxiety and can be understood as a trait which represents a fairly stable characteristic of an individual and that influences how an individual feels in, perceives, and evaluates specific situations. ${ }^{10}$ Math-anxious individuals experience increased levels of anxiety in math-related situations. State math anxiety manifests itself on an emotional, cognitive, and physiological level and leads to outcomes such as decreases in achievement. On an emotional level, individuals suffer from feelings of tension, apprehension, nervousness, and worry. ${ }^{1,18}$ On a cognitive level, math anxiety compromises the functioning of working memory (as described in greater detail further). ${ }^{19-21}$ 
On a physiological level, the symptoms of math anxiety include increased heart rate, clammy hands, upset stomach, and lightheadedness. ${ }^{4}$ Math anxiety and its feelings of tension, or assumptions that students may feel their heart beating faster when confronted with mathematical problems, have been objectively verified. ${ }^{22}$ Previous research has compared students' physiological reactivity while completing math tasks compared to those when completing anagrams. ${ }^{23}$ Students with high levels of math anxiety showed greater increases in cardiovascular reactivity when solving mathematical tasks than students with low levels of math anxiety, implying a higher level of strain due to math anxiety.

Neurocognitive research suggests that math anxiety and its affective responses are related to the fear and pain network in the brain. ${ }^{24}$ On a neural level, two networks represent the emotionality of math anxiety: the pain network involving the insula ${ }^{25}$ and the fear network centered around the amygdala. ${ }^{26}$ In functional MRI studies, activity in the insula's pain network can be observed when math-anxious individuals face a math task. ${ }^{25}$ Interestingly, not the task itself, but its anticipation correlates with pain-related activity. In a study focusing on the fear network, ${ }^{26}$ highly math-anxious children showed hyperactivity and an abnormal connectivity in the right basolateral amygdala, suggesting that the effects of math anxiety on these networks are age dependent. ${ }^{24}$

\section{A framework of math anxiety}

Math anxiety takes immediate effect in math-related situations such as examinations or in the classroom. However, it influences individuals over the course of their academic and vocational lives. To understand the influence of math anxiety on learning and learners' academic development, it should be regarded as one variable within an ensemble of environmentrelated and person-related variables that interact together.

Based on findings from learning and instruction and research on moderating and mediating variables of math anxiety, ${ }^{10,21}$ the following figure presents a framework for understanding math anxiety and its effects. It distinguishes between different types of variables:

- (Educational) outcome variables such as performance, learning behaviors, or choices are influenced by math anxiety. ${ }^{5,10}$ They have a long-term effect on the further development of math anxiety and related variables.

- Antecedents that influence the occurrence of math anxiety. These antecedents may be environment related, and include culture, the characteristics of educational systems, as well as parents' and teachers' attitudes toward math and their students and children. ${ }^{27}$ Furthermore, antecedents of math anxiety may be person related and include aspects such as trait anxiety or gender. ${ }^{10,13}$

- Variables that interact reciprocally with math anxiety. In this context, self-efficacy, self-concept, and motivation in math are described. These variables interact in the immediate learning process with each other. Furthermore, they influence each other on a long range. Together with math anxiety, these variables influence outcome variables. ${ }^{7,10}$

\section{Outcomes of math anxiety}

According to Figure 1, math anxiety influences various outcome variables, the most important of which are introduced here.

\section{Math anxiety and performance}

Studies on performance mainly focus on students in secondary education and university students. In contrast, our literature review found fewer studies in primary education.

Studies in secondary education (grades 6-12) nearly always find negative relationships between anxiety and performance in math which are mainly measured as points in achievement tests or as grades. Ashcraft and Krause write: "The story told by the correlations is sad indeed. The higher

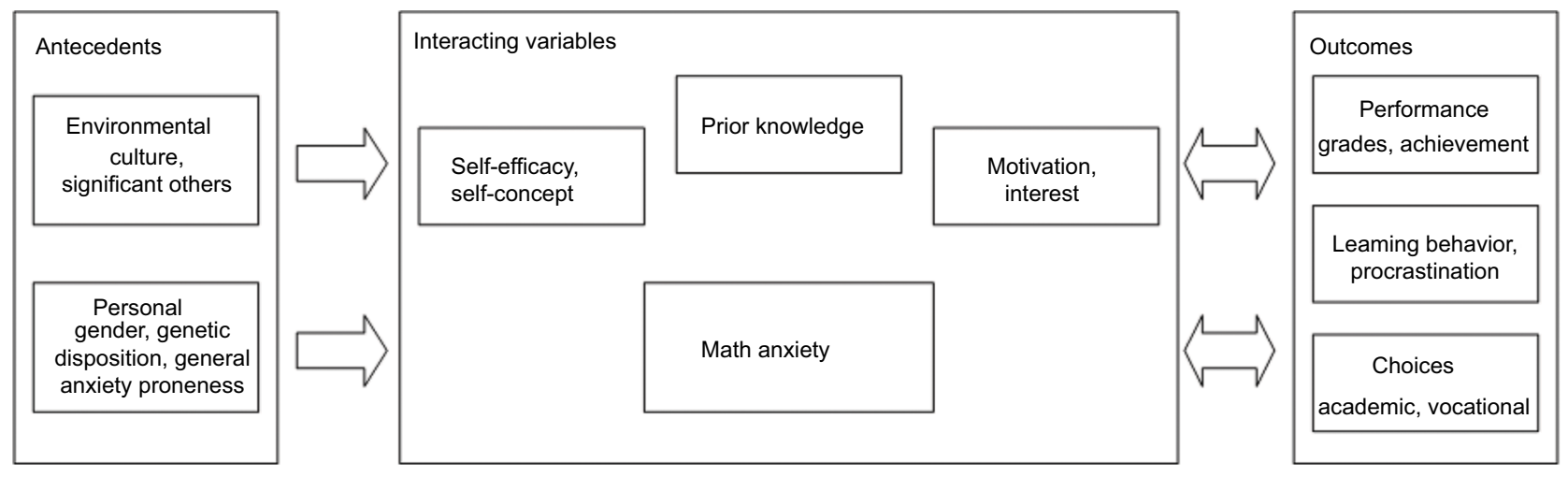

Figure I A framework for understanding math anxiety. 
one's math anxiety, the lower one's math learning, mastery, and motivation". ${ }^{28}$

Meta-analyses and studies with samples from different school grades confirm this and give an insight into the relationship, mostly by means of correlation: in a 1990 meta-analysis with seven studies and students in grades $5-12$, correlations varied between $r=-0.18$ and $r=-0.47 .{ }^{29} \mathrm{~A}$ study in the same year with students in grades 7-9 reported correlations of $r=-0.20 .{ }^{30}$ A meta-analysis in 1999 with 26 studies and all grades in secondary education found correlations between $r=-0.12$ and $r=-0.47 .{ }^{31}$ Data from the PISA studies with 15- to 16-year olds confirm these results on an international level. Within and across countries, math anxiety correlates negatively with PISA math task achievement. This relationship remained stable over several assessment periods. $^{7,32}$

These correlations between math anxiety and performance point at significant relationships that vary considerably in their size. Correlations of $r=-0.18$ mean a shared variance between math anxiety and performance of only $3.24 \%$; values of $r=-0.47$ mean $22.09 \%$ shared variance, which is a rather large amount of shared variance. Altogether, these figures suggest that math anxiety can only explain a part of task performance (yet, partly, a considerable one), and is one variable within an ensemble of several others.

The studies in primary education yield results similar to the ones in secondary education. In a meta-analysis with three studies in upper elementary education, correlations between various facets of math anxiety and performance ranged from $r=-0.19$ to $r=-0.49 .{ }^{31}$ This means a shared variance between $3.61 \%$ and $24.01 \%$. Math anxiety in early grades, such as Grade 2, influences math performance not only in the same grade but also in subsequent grades. ${ }^{33}$ However, it is unclear whether, in primary education, mathematical knowledge, in general, or only specific aspects of mathematical knowledge are affected by math anxiety. In three studies in lower primary education, in grades 1 and 2, math anxiety had a stronger effect on mathematical reasoning and knowledge of concepts than on numerical operations and counting skills. ${ }^{34-36}$ In contrast, in studies in upper elementary education, math anxiety was negatively related to achievement on tasks measuring different types of knowledge, conceptual knowledge, and where the application of mathematical operations were concerned. ${ }^{31}$ Furthermore, different facets of math anxiety seem to contribute differently to math performance in primary education. ${ }^{37,38}$ Altogether, more investigations are needed for this age group.
Research with university students shows rather ambiguous results. In a 1990 meta-analysis, correlations varied between $r=0.02$ and $r=0.57 .{ }^{29}$ In a study with freshmen psychology students, correlations of $r=-0.21$ for course anxiety and $r=-0.33$ for math test anxiety and grades in the final school year were found. ${ }^{10}$ Again, the correlations are significant, although shared variance ranges between only $4.41 \%$ and $10.89 \%$.

\section{Math anxiety, performance, and effects on working memory}

According to the Attentional Control Theory, efficient cognitive processing depends on two attentional systems: a top-down, goal-driven system that is influenced by current goals and expectations, and a stimulus-driven system that is influenced by the salient stimuli of the environment. ${ }^{39,40}$ Anxiety disrupts the balance between these two systems, causing the stimulus-driven system to become dominant, thus reducing the capacity to focus on task-relevant, instead of threat-related, information. This imbalance is connected to impairments in cognitive processing so that it becomes more difficult to resist the disruption of interference from taskirrelevant stimuli and to focus on task-relevant stimuli. ${ }^{41,42}$

Working-memory impairments involve specific aspects of mathematical proficiency, especially accuracy and procedural fluency. Whereas accuracy refers to the correctness of task solutions and the number of errors, fluency refers to the ability to apply procedures efficiently, within a short amount of time, and with minimal effort. Fluency depends on practice and includes the establishment of work routines. As such, fluency indicates familiarity with mathematical problems. Math anxiety appears to influence fluency more strongly than accuracy. Students with lower math anxiety are more efficient and complete more digits correctly per minute on mathematical tasks (with operations such as addition, subtraction, multiplication, division, and linear equations) than students with higher degrees of math anxiety. ${ }^{43}$ These assumptions, however, were verified for only adult students and not for children or adolescents who may be less fluent in mathematical task processing.

Math anxiety not only impairs genuine mathematical cognitive processes, but overarching cognitive processes that depend on fluency as well. In a study with undergraduate psychology students, students with medium or high math anxiety were impaired in their reading processes when the text was related to math. ${ }^{42}$ Similarly, specific declines in working-memory capacity were found when a computation task was administered, albeit not when participants worked on 
verbally based tasks. ${ }^{28,41}$ Math anxiety compromises reading speed as well as errors in task solving, although it depletes memory resources only for performance in math-related tasks, not in other domains. Recent research suggest that cognitive processes of forgetting math content are related to math anxiety. ${ }^{44}$

\section{Math anxiety and learning behaviors, especially procrastination}

Math anxiety not only has direct effects on task performance, but influences long-term learning as well. Students with high levels of math anxiety are prone to a variety of adverse learning behaviors: they invest less time and effort in learning, organize their learning environment less efficiently, and devote less concentration and attention to a learning session. ${ }^{10}$ Moreover, math-anxious students tend to avoid math-related situations and courses and more frequently exhibit procrastination behavior. ${ }^{45}$ Academic procrastination makes students postpone their involvement with academic tasks such as homework or preparation for examinations. In math, the acquisition of knowledge and skills and the development of fluency in carrying out tasks depends strongly on constant practice. Procrastination, therefore, has significant effects, setting off a vicious cycle when math-anxious students avoid preparing for math, perform below expectations in examinations, and probably develop even higher levels of math anxiety as a result. ${ }^{46}$

\section{Math anxiety and academic and vocational choices}

Math-anxious students take fewer math courses and avoid elective math coursework as early as secondary school., ${ }^{5,28}$ These choices influence the further development of knowledge and skills as well as attitudes and self-estimations as they relate to math. Consequently, at a later age, students with high levels of math anxiety regard themselves as less able in math and expect to do badly in exams. Math-anxious students (often females) avoid enrollment not only in math courses but also in related fields such as science, technology, and engineering. ${ }^{30,47}$

In a 1992 investigation with female freshmen college students, math anxiety was related to career interests and enrollment in courses in different disciplinary fields. ${ }^{48}$ Students were asked how likely it would be for them to choose a career in various fields and how happy they would be in the respective field. Math anxiety proved to be crucial when it came to exclusion from a career in science and engineering; here, interest and math anxiety had antagonistic effects. Interest in science and engineering were mostly associated with low levels of math anxiety and contributed positively to considering a career in these domains. Math anxiety and interest were more important for the students' career decisions than their knowledge of math, as measured by SAT (Scholastic Assessment Test) scores. ${ }^{48}$

\section{Antecedents of math anxiety}

Antecedents of math anxiety can be divided into personal and environmental characteristics. Personal antecedents refer to the individual (eg, prior knowledge, trait anxiety, or gender), whereas environmental antecedents include aspects such as educational or cultural values or the influence of other significant people in their own life.

\section{Significant people like teachers or parents}

Teachers, parents, and other important adults serve as role models and influence children with their own attitudes toward math. ${ }^{27,49}$ Teachers may spread the myth that math ability is inborn, and success depends on giftedness. In addition, they may emphasize that achievement in math depends on effort and persistence. In primary education, teachers have an especially significant influence, transferring their own anxiety in math to their students. ${ }^{49,50}$ Female elementary school teachers influence girls in particular; the teacher's level of math anxiety influences the achievement of the girls in their classes as well as the beliefs the girls maintain about their own mathematical abilities. ${ }^{51,52}$ Moreover, school teachers foster math anxiety if they exhibit their own negative attitudes toward math in the classroom..$^{53}$ In contrast, teachers support positive attitudes in math if they provide encouragement, emphasize that mistakes are also a part of successful learning, and if they appeal to their students' motivation and sense of self-efficacy and self-concept, for example, via accurate judgments of student performance and an accurate, yet selfassuring, feedback. ${ }^{54}$

Parents shape their children's educational values and self-assessments by their own attitudes toward math. Parents' beliefs about their child's ability have strong impacts on his or her self-assessment. These beliefs do not necessarily rely on objective assessments because parents may maintain stereotypical evaluations. ${ }^{55,56}$ Parents' attributions toward math serve as a frame of reference, meaning that they may transfer their own math anxiety to their children. Mothers, in particular, influence their daughters' attitudes toward math, self-assessments, and math anxiety. ${ }^{27}$

\section{Culture and educational systems}

According to the PISA studies, the level of math anxiety on the one side and the strength of the correlation between 
math-anxiety, self-assessments in math abilities, and performance on the other side differ across countries. ${ }^{7,32,57}$ Specific differences exist between Asian and Western European countries. Students in Asian countries, especially Korea, Japan, and Thailand, report low values on math self-concepts and self-efficacy and high math anxiety, whereas students in Western European countries such as Austria, Germany, Liechtenstein, Sweden, and Switzerland show high math self-efficacy and self-concept and low math anxiety. Asian students tend to set high goals and evaluate themselves according to strict standards. Additionally, they perceive their parents and themselves to be less satisfied with their school performance compared to non-Asian students. ${ }^{32,58}$ All of these elements contribute to high anxiety and low self-concept and self-efficacy. But when it comes to math anxiety, the European countries show a stronger association between math anxiety and performance than Asian countries. However, in all countries, math anxiety correlates (yet, to different degrees) with achievement on the PISA math tasks. ${ }^{32}$

\section{Gender and stereotypes}

Studies on math anxiety in secondary and tertiary education nearly always find higher levels of math anxiety in female, than in male, students. ${ }^{11,59-61}$ Gender inequalities seem to vary between the different facets of math anxiety. Women score higher on math test anxiety than men. At least in university education, the results for the content-related facets such as numerical anxiety are more ambiguous; here, studies display greater disagreement on gender differences. Some studies find gender differences for all facets of math anxiety ${ }^{10,13}$ whereas, in other studies, women score higher than men on test anxiety but men score higher on numerical anxiety. ${ }^{62}$ Here, more fine-tuned research on gender differences in the different facets of math anxiety seems necessary.

Studies in secondary education confirm a gender bias in math anxiety. ${ }^{60}$ With basically all facets of math anxiety, girls score higher than boys. This holds true for all grades. ${ }^{12,59,63}$ In a majority of PISA study countries, ${ }^{7}$ girls (aged 15-16) scored higher than boys on test, classroom, and numerical anxiety. Interestingly, gender differences in math anxiety were widest in countries that have comparatively low levels of math anxiety. ${ }^{32}$

To prevent math anxiety at an early age, it would be important to know at which age gender differences come into being. Research on younger children, however, provides no clear picture. In a 2012 study, children between the ages of 7.5 and 9.4 years were asked how worried/relaxed they are about working on math tasks, about math tests, or understand- ing the teacher in a math class. No gender differences were found for this sample. ${ }^{64}$ This result was confirmed in studies in different countries and with different age groups: with a sample of 136 children between 7 and 10 years and measures of numerical, homework/classroom, and test anxiety in Germany; ${ }^{17}$ with a sample of 8 -year-old children and measures of classroom and test anxiety in the Netherlands; ${ }^{65}$ with a sample of 6- to 7-year-olds and measures of worry in the United States; ${ }^{34}$ and with a sample of 7- to 9-year-olds and an overall measure of math anxiety also in the United States. ${ }^{66}$ In contrast, in a recent study in 2017 with samples of British children aged 8-9, girls scored higher on numerical and test anxiety. ${ }^{12}$ Although the majority of studies speak against gender differences in primary education, the results still are not clear-cut. Studies nearly exclusively use a cross-sectional design. There is a need for long-term studies in which the development of gender differences in math anxiety can be observed over children's formative years.

A large part of gender differences in math anxiety can be attributed to stereotypes about females' abilities in math (as well as in science, technology, and engineering). ${ }^{55,59}$ Girls internalize stereotypes about lower abilities in math and regard themselves as being less gifted than boys. These kinds of self-depreciatory assessments influence learning behaviors as well as math anxiety. In assessment situations, the internalized stereotype affects the perception of task difficulty and is related to increased strain and tension as well as decreased performance. ${ }^{55,67}$ Over the course of childhood and adolescence, self-depreciatory assessment and anxiety lead to avoidance of math, harmful learning behaviors, and lower performance..$^{57,61}$

In addition to these effects, studies suggest that at least a smaller part of gender differences is due to hereditary influences. In their twin studies with comparisons of females and males, Malanchini et $\mathrm{al}^{68}$ observed differences but sex only accounted for between $1.3 \%$ and $5.5 \%$ of the variance. This result, together with the research results described earlier, speaks for a large influence of individuals' environment and stereotypes concerning girls' and women's aptitude in math, with a smaller influence of sex.

\section{Genetic dispositions}

Studies with monozygotic and dizygotic twins suggest that math anxiety has a genetic component, too. ${ }^{68,69}$ The hereditary contribution to math anxiety can be investigated by comparisons of monozygotic and dizygotic twins. Monozygotic twins share $100 \%$ and dizygotic twins only $50 \%$ of their segregating alleles. A study with 12 -year-old ${ }^{69}$ as well as 
one with 19- to 20 -year-old twin pairs ${ }^{68}$ showed a moderate hereditary contribution to math anxiety, with environmental influences explaining the rest of the variance. Individuals with a hereditary disposition are more likely to develop math anxiety. However, more research is needed as the role of the genetic influence in comparison to the influence of family and school environment is still unclear.

A disposition that has a high comorbidity with math anxiety is dyscalculia. When children have weaknesses in mathematical skills and experience difficulties and negative feedback, they often develop math anxiety, too. Approximately $1-6 \%$ of children are assumed to suffer from dyscalculia. ${ }^{70}$ They need specific interventions and support that considers their specific handicaps as well as math anxiety. However, an analysis of treatments for this group would go beyond the scope of this article with its focus on individuals with mainly unimpaired math skills.

\section{General anxiety proneness}

General anxiety proneness can be described as the habitual tendency to perceive stressful situations as threatening. ${ }^{1,10,18,71}$ Endler and Kocovski ${ }^{72}$ also use the term "trait anxiety". General anxiety proneness describes relatively stable individual differences in general proneness to anxiety. ${ }^{18}$ Therefore, a domain-specific form of anxiety should be related to general anxiety proneness. In a meta-analysis with samples of children and young adults, general and math anxiety correlated significantly with coefficients ranging from $r=0.24$ to $r=0.54 .{ }^{29}$ However, the strength of the relationship differs for the various facets of math anxiety; test and classroom anxiety pertaining to math are more closely related to general anxiety proneness than numerical anxiety. ${ }^{10}$ Studies of the hereditary influence on general anxiety and math anxiety show that both types of anxiety have a small degree of shared, but a larger degree of unshared, components. ${ }^{68,69}$

\section{Variables in reciprocal interaction with math anxiety}

Figure 1 suggests that math anxiety reciprocally interacts with other variables in math-related situations. The most important variables are introduced further.

\section{Self-efficacy and self-concept}

With regard to math, self-efficacy describes the belief of a person that, through their own action and effort, one can successfully perform in math. ${ }^{7}$ The self-concept is related to self-efficacy, but is more focused on beliefs in academic domains. ${ }^{73}$ It describes an individual's beliefs in his or her competence in comparison to a standard of knowledge, to other learners' knowledge, or an assessment of a person's own development in an academic domain. ${ }^{73}$

Overall, self-efficacy and self-concept in math are positively related to performance and negatively to math anxiety; the PISA studies demonstrate this quite impressively for all participating countries. ${ }^{7}$ However, the self-concept is not an accurate reflection of actual competence in a domain, but instead, is influenced by stereotypes. ${ }^{55}$ Self-concept, anxiety, and performance in math influence each other in the long term. High performance may boost self-concept and decrease anxiety, whereas a higher self-concept and lower anxiety levels inspire motivation in learning and reduce negative learning behaviors such as procrastination. ${ }^{10,73,74}$

\section{Prior knowledge}

Lack of knowledge or the inability to understand mathematical concepts strongly contribute to math anxiety. ${ }^{4}$ According to the Reciprocal Theory, ${ }^{70}$ poor performance triggers math anxiety, and math anxiety leads to poor performance in a task-related situation. As described earlier, math anxiety is related to cognitive processing deficits in the working memory and, consequently, to poor performance and poor uptake of knowledge in task-related situations. ${ }^{29}$

Furthermore, math anxiety prevents long-term learning and knowledge acquisition in math: learners with math anxiety avoid math-related courses and tasks over the course of time. In situations where processing mathematical content cannot be avoided, they show decreases in cognitive reflection on the task at hand. ${ }^{75}$ Shorter and more shallow contact with math then leads to low levels of knowledge and skills.

\section{Motivation}

Motivation can be described as an individual preference and a positively experienced, situation-specific state when working on a task. Students with higher motivation in a subject invest more time and effort in learning and performance and apply more effective learning strategies. ${ }^{74}$ While motivation describes the tendency to approach, anxiety describes the tendency to avoid a task or a situation.

Very few studies however investigate the interaction between motivation, math anxiety, and performance. Against this background, Wang et $\mathrm{al}^{76}$ doubt the numerous research results which assume a direct linear, negative correlation between math anxiety and performance. Research on state anxiety and performance on complex tasks mostly assumes a curvilinear relationship according to the Yerkes-Dodson law. Here, an intermediate level of stress produces optimal 
performance, whereas extremely low and high levels of stress produce poor performance. It seems that intrinsic motivation changes the relationship between math anxiety and performance. In studies with children and adults, a linear, negative correlation between math anxiety and performance was found for learners with low levels of motivation and a curvilinear correlation for learners with high levels of motivation in math. ${ }^{76}$ For learners with high intrinsic motivation, a moderate degree of math anxiety may have beneficial effects.

Findings on the long-term effects of anxiety and learning behaviors support this notion. Anxiety may induce the motivation to avoid failure and its negative consequences. If the consequences of failure are severe (eg, dropping out of a course), and if students believe that there is a chance for success, math anxiety induces them to invest effort and time and strengthens positive effort motivation. Math anxiety, the expectation of success, and motivation interact with each other. ${ }^{10,33,74}$

\section{Assessment of math anxiety}

In both education and research, it is necessary to assess math anxiety and compare different individuals' levels of it. Math anxiety is nearly exclusively assessed using questionnaires with rating scales; this is done for all age groups.

The two most widely used math anxiety questionnaires for adults are, without question, the Mathematics Anxiety Rating Scale (MARS) and its short version, the Revised Mathematics Anxiety Rating Scale (R-MARS). ${ }^{16,77}$ The items describe different situations applying math: studying for a math test, taking an exam, processing math in a daily-life situation, etc. Individuals assess the level of anxiety in the respective situation on a Likert scale. Both questionnaires distinguish different facets of math anxiety according to the type of situation: test anxiety, math course anxiety, computation anxiety, anxiety to apply math in daily life, and fear of math teachers. ${ }^{62}$ Different types of validity were assessed positively: content validity as rated by experts, structural validity by an examination of the factorial structure, and criterion-related validity by the relationship to grades, to performance on standardized math tests, and to states of anxiety in math-related situations. ${ }^{11,62,77,78}$ The MARS is one of the most comprehensive questionnaires concerning the inclusion of different facets of math anxiety. Shorter questionnaires mostly focus only on math test anxiety and numerical anxiety - for example, the Abbreviated Math Anxiety Scale (AMAS). ${ }^{11,13}$

Questionnaires for students in secondary education are often variations of the instruments for adults. An example is the MARS-E (elementary form) for children grades 4 onwards, which means age 10 to adolescence. ${ }^{79}$ The items describe situations in school and children's daily life. As with the version for adults, children and adolescents assess the level of anxiety they experience in their respective situations.

Questionnaires for younger children need to correspond to the respective developmental level including reading skills. Most questionnaires attempt to do this by using items with very concrete math-related situations from children's daily life and rating scales with illustrative icons like smileys (for an overview, see Ganley and $\mathrm{McGraw}^{14}$ ). However, it can be discussed whether these adaptations adequately reflect children's level of understanding.

An innovative questionnaire for children aged 7-10 is the Mathematics Anxiety Interview (MAI). ${ }^{17}$ Here, children look at pictures of math-related situations and receive a corresponding text description. They then assess their emotional, cognitive, physiological reactions and behaviors in the situation on a Likert scale, which means how excited they feel in such a situation, how worried they are, how strongly their heart beats, or whether they would like to escape from the situation. The children, furthermore, assess their overall anxiety in the situation. To our knowledge, the MAI is the only questionnaire with this kind of fine-tuned assessment of the different types of possible reactions to anxiety.

Our literature review found only one questionnaire for even younger children aged 6-8. Aarnos and Perkkilä developed a test in which children describe their feelings with regard to pictures with or without mathematical content. Furthermore, children are asked to draw pictures which are evaluated by content analysis. ${ }^{80,81}$ While this kind of assessment requires no reading skills, the reliability of its evaluation does, in fact, pose a problem.

Altogether, questionnaires vary with regard to the age group and the facets of math anxiety they measure. While some take a narrow approach and include only a few facets, others include a wide range of math anxiety aspects. Nearly all questionnaires (with the exception of the MAI) rely on a global assessment of anxiety. Questionnaires vary with regard to how precisely they focus on math anxiety. Some measure not only math anxiety but, under the umbrella of math anxiety, they even subsume concepts that are related to math anxiety while measuring different concepts such as self-concept. ${ }^{14,82}$

\section{Implications for practice, means to prevent or reduce math anxiety}

In light of the severe impairments to individuals' lives, the question arises of how math anxiety can be prevented or at 
least alleviated. Measures may aim to directly reduce math anxiety or to counteract math anxiety by strengthening an individual's positive assessments and attitudes or by supporting efficient learning. Measures against math anxiety can be taken by educational institutions, teachers, parents, or the affected person.

At the institutional level, curricular strategies against math anxiety may be implemented. Various colleges already offer courses against math anxiety wherein students learn techniques to overcome barriers in learning math and handle their fear of the subject. ${ }^{83}$ Educational institutions may also provide the opportunity to take tests several times and give test-anxious students an emotional safety net. Even if students do not use a retest, the opportunity itself eases strain. ${ }^{83,84}$ Some institutions attempt to reduce math anxiety by improving students' knowledge, for example, by introductory math courses for freshmen. ${ }^{85}$

Teachers may choose instructional strategies that enhance students' interest and motivation, for example, by relating math to students' lives and to daily-life situations. ${ }^{4}$ Math instruction and tasks should be attractive to both males and females and, thus, prevent the formation of stereotypes. Similar advice involves the use of hands-on devices and manipulatives in learning. ${ }^{4,83}$ Such instructional measures may enhance motivation, self-efficacy, and self-concept, as well as success, and counteract math anxiety as a result. Math anxiety can be reduced by the development of a positive yet realistic self-concept in math - all while keeping in mind that improvements in students' self-concept will be short-lived without enhancing knowledge acquisition and improving achievement.

In exams, teachers may introduce anxiety-reducing measures such as using humorous examination tasks, or dividing the learning contents into several smaller examinations instead of one extensive examination. ${ }^{21}$ Given that pressure enhances math anxiety and its effects in examinations, teachers should set enough time for math examinations and avoid time constraints. ${ }^{86}$

Parents may support their children in developing a positive self-concept and preventing the development of math anxiety by, for example, providing adequate feedback or praise to achievement in math, by maintaining realistic expectations for their children's success in math, or by showing how math is used in positive ways, such as in sports, hobbies, home repair, etc. ${ }^{4}$

Learners can protect themselves against the development of math anxiety by different means. These involve the realistic attribution of success and failure to one's abilities or effort and the development of a positive yet realistic self-concept. Learners should focus more on past successes than failures, and believe in their abilities instead of doubting them. ${ }^{4}$ Other measures concern positive learning behaviors, for example, leaving enough study time for repetition of the material to be mastered, allotting enough time to study, and avoiding procrastination. ${ }^{4,21,74}$ In math-related situations, students may use relaxation techniques to alleviate their anxiety level., ${ }^{4,87}$ Another means for reducing exam anxiety is reappraisal, which means a change in a situation's evaluation and its potentially threatening characteristics over to more positive attributes. ${ }^{88,89}$

However, our research review on interventions to math anxiety showed a limited range of studies. Studies on the topic need a more systematic approach. Presently, studies focus on different outcomes of math anxiety, on different age groups; they mostly investigate various smaller interventions over a short time period. For the advancement of interventions on math anxiety, a clinimetric framework with a joint understanding and description of the phenomenon itself, of rating scales, and indexes for measurement of math anxiety as well as for success of interventions would be helpful.

\section{Conclusion}

In both research and practice, it has been acknowledged on an international level that math anxiety poses a severe problem over entire life spans. The effects of math anxiety on performance have been widely investigated, and its negative impact has been acknowledged. Issues, however, still remain with regard to math anxiety that need further investigation.

One concerns the temporal development of math anxiety and (methodologically) the need for long-term investigations. There is still a lack of research on the question of how math anxiety develops in childhood and how it becomes established over time. More knowledge on this question could help prevent math anxiety at an early age. Long-term studies that cover a formative phase in children's development are advisable.

Another issue concerns the relationship between math anxiety and moderating variables. As could be shown for intrinsic motivation, moderating variables may change the relationship between math anxiety and performance; when learners experienced intrinsic motivation, moderate levels of math anxiety had a positive influence on performance. Here, methodological and statistical approaches are needed that take into consideration the reciprocal interaction of an ensemble of variables. 
Lastly, as it was pointed out in the last section, research on math anxiety would very much profit from a more standardized clinimetric approach and joint agreements of researchers and practitioners on how to define and measure math anxiety.

As shown, there are numerous possibilities for the support of math-anxious individuals and reducing math anxiety. More knowledge on the development of math anxiety and its interaction with other variables will be important in supporting math-anxious individuals. Ideally, countermeasures should ultimately be offered that are tailored specifically to each individual's personality, knowledge, and needs.

\section{Disclosure}

The authors report no conflicts of interest in this work.

\section{References}

1. Papousek I, Ruggeri K, Macher D, et al. Psychometric evaluation and experimental validation of the Statistics Anxiety Rating Scale. J Pers Assess. 2012;94(1):82-91.

2. Somers JM, Goldner EM, Waraich P, Hsu L. Prevalence and incidence studies of anxiety disorders: a systematic review of the literature. Can J Psychiatry. 2006;51(2):100-113.

3. Rickwood D, Bradford S. The role of self-help in the treatment of mild anxiety disorders in young people: an evidence-based review. Psychol Res Behav Manag. 2012;5:25-36.

4. Blazer C. Strategies for Reducing Math Anxiety [Information capsule]. 2011; 1102. Available from: https://eric.ed.gov/?id=ED536509. Accessed February 19, 2018.

5. 5 Ashcraft MH, Moore AM. Mathematics anxiety and the affective drop in performance. J Psychoeduc Assess. 2009;27(3):197-205.

6. Johnston-Wilder S, Brindley J, Dent P. A Survey of Mathematics Anxiety and Mathematical Resilience Among Existing Apprentices. London: Gatsby Charitable Foundation; 2014. Available from: http://wrap. warwick.ac.uk/73857/. Accessed July 16, 2018.

7. OECD - The Organisation for Economic Co-operation and Development. PISA 2012 Results: Ready to Learn (Volume III): Students, Engagement, Drive and Self-Beliefs. Paris: OECD Publishing; 2013. Available from: http://dx.doi.org/10.1787/9789264201170-en. Accessed July 16, 2018.

8. American Psychiatric Association. Diagnostic and Statistical Manual of Mental Disorders. 5th ed. Seattle, WA: APA; 2013.

9. World Health Organization. The ICD-10 Classification of Mental and Behavioural Disorders: Clinical Descriptions and Diagnostic Guidelines. 10th ed. Geneva: WHO;1992.

10. Paechter M, Macher D, Martskvishvili K, Wimmer S, Papousek I. Mathematics anxiety and statistics anxiety. Shared but also unshared components and antagonistic contributions to performance in statistics. Front Psychol. 2017;8:1196.

11. Hopko DR, Mahadevan R, Bare RL, Hunt MK. The Abbreviated Math Anxiety Scale (AMAS): construction, validity, and reliability. Assessment. 2003;10(2):178-182.

12. Carey E, Hill F, Devine A, Szücs D. The Modified Abbreviated Math Anxiety Scale: a valid and reliable instrument for use with children. Front Psychol. 2017;8:11.

13. Cipora K, Szczygieł M, Willmes K, Nuerk HC. Math anxiety assessment with the Abbreviated Math Anxiety Scale. Applicability and usefulness: insights from the Polish adaptation. Front Psychol. 2015;6:1833.
14. Ganley CM, McGraw AL. The development and validation of a revised version of the Math Anxiety Scale for Young Children. Front Psychol. 2016;7:1181.

15. Kazelskis R. Some dimensions of mathematics anxiety: a factor analysis across instruments. Educ Psychol Meas. 1998;58(4):623-633.

16. Baloğlu M, Zelhart PF. Psychometric properties of the Revised Mathematics Anxiety Rating Scale. Psychol Rec. 2007;57(4):593-611.

17. Kohn J, Richtmann V, Rauscher L, et al. Das Mathematikangstinterview (MAI): Erste psychometrische Gütekriterien [Math Anxiety Interview (MAI): First Psychometric Properties]. Lernen und Lernstörungen. 2013;2(3):177-189. German.

18. Spielberger CD. Anxiety, cognition and affect: a state-trait perspective. In: Tuma AH, Maser J, editors. Anxiety and the Anxiety Disorders. Hillsdale, NJ: Lawrence Erlbaum Associates, Inc.; 1985:171-182.

19. Cassady JC, Johnson RE. Cognitive test anxiety and academic performance. Contemp Educ Psychol. 2002;27(2):270-295.

20. Eysenck MW, Derakshan N, Santos R, Calvo MG. Anxiety and cognitive performance: attentional control theory. Emotion. 2007;7(2): 336-353.

21. Macher D, Paechter M, Papousek I, Ruggeri K. Statistics anxiety, trait anxiety, learning behavior, and academic performance. Eur J Psychol Educ. 2012;27(4):483-498.

22. Sheffield D, Hunt T. How does anxiety influence maths performance and what can we do about it? MSOR Connections. 2006;6(4):19-23.

23. Faust MW. Analysis of Physiological Reactivity in Mathematics Anxiety [dissertation]. Bowling Green, OH: Bowling Green State University; 1992.

24. Artemenko C, Daroczy G, Nuerk H-C. Neural correlates of math anxiety - an overview and implications. Front Psychol. 2015;6:1333.

25. Lyons IM, Beilock SL. Mathematics anxiety: Separating the math from the anxiety. Cereb Cortex. 2012;22(9):2102-2110.

26. Young CB, Wu SS, Menon V. The neurodevelopmental basis of math anxiety. Psychol Sci. 2012;23(5):492-501.

27. Casad BJ, Hale P, Wachs FL. Parent-child math anxiety and math-gender stereotypes predict adolescents' math education outcomes. Front Psychol. 2015;6:1597.

28. Ashcraft MH, Krause JA. Working memory, math performance, and math anxiety. Psychon Bull Rev. 2007;14(2):243-248.

29. Hembree R. The nature, effects, and relief of mathematics anxiety. $J$ Res Math Educ. 1990;21(1):33-46.

30. Meece JL, Wigfield A, Eccles JS. Predictors of math anxiety and its influence on young adolescents' course enrollment intentions and performance in mathematics. J Educ Psychol. 1990;82(1):60-70.

31. Ma X, Xu J. The causal ordering of mathematics anxiety and mathematics achievement: a longitudinal panel analysis. J Adolesc. 2004;27(2):165-179.

32. Lee J. Universals and specifics of math self-concept, math self-efficacy, and math anxiety across 41 PISA 2003 participating countries. Learn Individ Differ. 2009;19(3):355-365.

33. Skaalvik EM. Mathematics anxiety and coping strategies among middle school students: relations with students' achievement goal orientations and level of performance. Soc Psychol Educ. 2018;21:709-723. doi: 10.1007/s11218-018-9433-2.

34. Harari RR, Vukovic RK, Bailey SP. Mathematics anxiety in young children: an exploratory study. J Exp Educ. 2013;81(4):538-555.

35. Wu SS, Barth M, Amin H, Malcarne V, Menon V. Math anxiety in second and third graders and its relation to mathematics achievement. Front Psychol. 2012;3:162.

36. Chen L, Bae SR, Battista C, et al. Positive attitude toward math supports early academic success: behavioral evidence and neurocognitive mechanisms. Psychol Sci. 2018;29(3):390-402.

37. Cargnelutti E, Tomasetto C, Passolunghi MC. How is anxiety related to math performance in young students? A longitudinal study of Grade 2 to Grade 3 children. Cogn Emot. 2017;31(4):755-764.

38. Sorvo R, Koponen T, Viholainen H, et al. Math anxiety and its relationship with basic arithmetic skills among primary school children. $\mathrm{Br} J$ Educ Psychol. 2018;87(3):309-327. 
39. Eysenck MW, Calvo MG. Anxiety and performance: the processing efficiency theory. Cogn Emot. 1992;6(6):409-434.

40. Derakshan N, Eysenck MW. Anxiety, processing efficiency, and cognitive performance. Eur Psychol. 2009;14(2):168-176.

41. Ashcraft MH, Kirk EP. The relationships among working memory, math anxiety, and performance. J Exp Psychol Gen. 2001;130(2): 224-237.

42. Hopko DR, Ashcraft MH, Gute J, Ruggiero KJ, Lewis C. Mathematics anxiety and working memory. J Anxiety Disord. 1998;12(4): 343-355.

43. Cates GL, Rhymer KN. Examining the relationship between mathematics anxiety and mathematics performance: an instructional hierarchy perspective. J Behav Educ. 2003;12(1):23-34.

44. McDonough IM, Ramirez G. Individual differences in math anxiety and math self-concept promote forgetting in a directed forgetting paradigm. Learn Individ Differ. 2018;64:33-42.

45. Akinsola MK, Tella A, Tella A. Correlates of academic procrastination and mathematics achievement of university undergraduate students EURASIA J Math Sci Tech Ed. 2007;3(4):363-370. doi:10.12973/ ejmste/75415.

46. Okoiye OE, Okezie NE, Nlemadim MC. Impact of academic procrastination and study habit on expressed mathematics anxiety of junior secondary school students in Esan South-East Edo State Nigeria. $\mathrm{Br} J$ Psychol Res. 2017;5(1):32-40.

47. Foley AE, Herts JB, Borgonovi F, Guerriero S, Levine SC, Beilock SL. The math anxiety-performance link: a global phenomenon. Curr Dir Psychol Sci. 2017;26(1):52-58.

48. Chipman SF, Krantz DH, Silver R. Mathematics anxiety and science careers among able college women. Psychol Sci. 1992;3(5) 292-296.

49. Tobias S. Overcoming Math Anxiety: Revised and Expanded. New York: Norton; 1993.

50. Furner JM, Berman BT. Review of research: Math anxiety: Overcoming a major obstacle to the improvement of student math performance. Child Educ. 2003;79(3):170-174.

51. Beilock SL, Gunderson EA, Ramirez G, Levine SC. Female teachers' math anxiety affects girls' math achievement. Proc Natl Acad Sci U S A. 2010;107(5):1860-1863.

52. Jackson CD, Leffingwell RJ. The role of instructors in creating math anxiety in students from kindergarten through college. Math Teach 1999;92(7):583-586.

53. Lin Y, Durbin JM, Rancer, AS. Perceived instructor argumentativeness, verbal aggressiveness, and classroom communication climate in relation to student state motivation and math anxiety. Comm Educ. 2018;66(3):330-349.

54. Urhahne D, Chao SH, Florineth ML, Luttenberger S, Paechter M. Academic self-concept, learning motivation, and test anxiety of the underestimated student. Br J Educ Psychol. 2011;81(Pt 1):161-177.

55. Ertl B, Luttenberger S, Paechter M. The impact of gender stereotypes on the self-concept of female students in STEM subjects with an underrepresentation of females. Front Psychol. 2017;8:703.

56. Rodriguez-Planas N, Nollenberger N. Let the girls learn! It is not only about math ... it's about gender social norms. Econ Educ Rev 2018;62:230-252.

57. OECD - The Organisation for Economic Co-operation and Development. The ABC of Gender Equality in Education. Paris: OECD Publishing; 2015. Available from: http://dx.doi.org/10.1787/9789264229945-en.

58. Whang PA, Hancock GR. Motivation and mathematics achievement: comparisons between Asian-American and non-Asian students. Contemp Educ Psychol. 1994;19(3):302-322.

59. Bieg M, Goetz T, Wolter I, Hall NC. Gender stereotype endorsement differentially predicts girls' and boys' trait-state discrepancy in math anxiety. Front Psychol. 2015;6:1404

60. Dowker A, Sarkar A, Looi CY. Mathematics anxiety: What have we learned in 60 years? Front Psychol. 2016;7:508.

61. Else-Quest NM, Hyde JS, Linn MC. Cross-national patterns of gender differences in mathematics: a meta-analysis. Psychol Bull. 2010;136(1):103-127.
62. Baloğlu M, Koçak R. A multivariate investigation of the differences in mathematics anxiety. Pers Individ Dif. 2006;40(7):1325-1335.

63. Wigfield A, Meece JL. Math anxiety in elementary and secondary school students. J Educ Psychol. 1988;80(2):210-216.

64. Dowker A, Bennett K, Smith L. Attitudes to mathematics in primary school children. Child Dev Res. 2012;2012:124939.

65. Erturan S, Jansen B. An investigation of boys' and girls' emotional experience of math, their math performance, and the relation between these variables. Eur J Psychol Educ. 2015;30(4):421-435.

66. Jameson MM. Contextual factors related to math anxiety in secondgrade children. $J$ Exp Educ. 2014;82(4):518-536.

67. Macher D, Papousek I, Ruggeri K, Paechter M. Statistics anxiety and performance: blessings in disguise. Front Psychol. 2015;6:1116.

68. Malanchini M, Rimfeld K, Shakeshaft NG, et al. The genetic and environmental aetiology of spatial, mathematics and general anxiety. Sci Rep. 2017;21(7):42218.

69. Wang Z, Hart SA, Kovas Y, et al. Who's afraid of math? Two sources of genetic variance for mathematical anxiety. $J$ Child Psychol Psychiatry. 2014;55(9):1056-1064.

70. Carey E, Hill F, Devine A, Szücs D. The chicken or the egg? The direction of the relationship between mathematics anxiety and mathematics performance. Front Psychol. 2016;6:1987.

71. Meijer J. Stress in the relation between trait and state anxiety. Psychol Rep. 2001;88(Suppl 3):947-964.

72. Endler NS, Kocovski NL. State and trait anxiety revisited. J Anxiety Disord. 2001;15(3):231-245.

73. Marsh HW, Scalas LF. Self-concept in learning: reciprocal effects model between academic self-concept and academic achievement. In: Järvelä S, editor. Social and Emotional Aspects of Learning. Amsterdam: Elsevier Academic. Press; 2011:191-197.

74. Macher D, Paechter M, Papousek I, Ruggeri K, Freudenthaler HH, Arendasy M. Statistics anxiety, state anxiety during an examination, and academic achievement. Br J Educ Psychol. 2013;83(4):535-549.

75. Morsanyi K, Busdraghi C, Primi C. Mathematical anxiety is linked to reduced cognitive reflection: a potential road from discomfort in the mathematics classroom to susceptibility to biases. Behav Brain Funct. 2014; $10: 31$

76. Wang Z, Lukowski SL, Hart SA, et al. Is math anxiety always bad for math learning? The role of math motivation. Psychol Sci. 2015;26(12):1863-1876.

77. Richardson FC, Suinn RM. The Mathematics Anxiety Rating Scale: psychometric data. J Couns Psychol. 1972;19(6):551-554.

78. Suinn RM, Winston EH. The Mathematics Anxiety Rating Scale, a brief version: psychometric data. Psychol Rep. 2003;92(1):167-173.

79. Suinn RM, Taylor S, Edwards RW. Mathematics Anxiety Rating Scale for Elementary school students (MARS-E): psychometric and normative data. Educ Psychol Meas. 1988;48(4):979-986.

80. Aarnos E, Perkkilä P. Early signs of mathematics anxiety? Proc Soc Behav Sci. 2012;46:1495-1499.

81. Perkkilä P, Aarnos E. Children's mathematical and emotional expressions inspired by pictures. In: Hoskonen K, Hannula MS, editors. Current State of Research on Mathematical Beliefs XII. Proceedings of the MAVI-7 Workshop. May 25-28, 2006; Helsinki: University of Helsinki:83-96.

82. Krinzinger H, Kaufmann L, Dowker A, et al. Deutschsprachige Version des Fragebogens für Rechenangst (FRA) für 6- bis 9-jährige Kinder [A German version of the math anxiety questionnaire (FRA) for children between 6 and 9 years]. Z Kinder Jugendpsychiatr Psychother. 2007;35(5):341-351. German.

83. Iossi L. Strategies for reducing math anxiety in post-secondary students. In: Nielsen SM, Plakhotnik MS, editors. Proceedings of the Sixth Annual College of Education Research Conference: Urban and International Education Section. Miami, FL: Florida International University; 2007:30-35. http://education.fiu.edu/research_conference/docs/proceedings/2007_COERC_Proceedings.pdf. Accessed February 20, 2018.

84. Juhler SM, Rech JF, From SG, Brogan MM. The effect of optional retesting on college students' achievement in an individualized algebra course. J Exp Educ. 1998;66(2):125-137. 
85. Logue AW, Watanabe-Rose M, Douglas D. Should students assessed as needing remedial mathematics take college-level quantitative courses instead? A randomized controlled trial. Educ Eval Policy Anal. 2016;38(3):578-598.

86. Passolunghi MC, Caviola S, Agostini R de, Perin C, Mammarella IC. Mathematics anxiety, working memory, and mathematics performance in secondary-school children. Front Psychol. 2016;7:42.

87. Furner JM, Gonzalez-DeHass A. How do students' mastery and performance goals relate to math anxiety? EURASIA J Math Sci Tech Ed. 2011;7(4):227-242.
88. Perchtold CM, Fink A, Rominger C, et al. Reappraisal inventiveness: impact of appropriate brain activation during efforts to generate alternative appraisals on the perception of chronic stress in women. Anxiety Stress Coping. 2018;31(2):206-221.

89. Pizzie R, Kraemer DJ. The Influence of Emotion Regulation Techniques on Arousal and Performance in Math Anxiety. Available from: http:// doi.org/10.17605/OSF.IO/F3D59. Accessed January 22, 2018.

\section{Publish your work in this journal}

Psychology Research and Behavior Management is an international, peerreviewed, open access journal focusing on the science of psychology and its application in behavior management to develop improved outcomes in the clinical, educational, sports and business arenas. Specific topics covered in the journal include: Neuroscience, memory and decision making; Behavior modification and management; Clinical applications; Business and sports performance management; Social and developmental studies; Animal studies. The manuscript management system is completely online and includes a very quick and fair peer-review system, which is all easy to use. Visit http://www. dovepress.com/testimonials.php to read real quotes from published authors. 